\title{
Detailed Kinetic Mechanism of Gas-Phase Reactions of Volatiles Released from Biomass Pyrolysis
}

Paulo Eduardo Amaral Debiagi, Giancarlo Gentile, Matteo Pelucchi, Alessio Frassoldati, Alberto Cuoci, Tiziano Faravelli, Eliseo Ranzi*

Dipartimento di Chimica Materiali ed Ingegneria Chimica "G. Natta"

Politecnico di Milano, Piazza Leonardo da Vinci 32, 20133 Milano, Italy

Corresponding author: Prof. Eliseo Ranzi

eliseo.ranzi@polimi.it

This is the accepted manuscript of paper available at:

https://doi.org/10.1016/j.biombioe.2016.06.015

\section{Highlights}

- A predictive model of biomass pyrolysis, gasification, and combustion is discussed.

- A lumped approach to describe biomass pyrolysis products is presented.

- The role of successive reactions of tar components is investigated.

- Secondary gas phase reactions of released volatiles are analyzed.

- Generic rate rules for oxygenated species are highlighted. 


\begin{abstract}
Comprehensive chemical models to describe the behavior of biomass pyrolysis, gasification and combustion are crucial for the simulation and design of thermochemical processes of ligno-cellulosic materials. Despite this importance, reliable and predictive models are still not well known. The original aspect of this work is to present a comprehensive and predictive model of pyrolysis, gasification, and combustion, starting from biomass characterization, through the description of released volatiles at the particle scale, until the effect of the secondary gas-phase reactions at the reactor scale. All these aspects can play a relevant role in the biomass thermo-valorization processes. Most of released species from biomass devolatilization are oxygenated hydrocarbons. This study aims at identifying some reference rate parameters, based on analogy and thermochemistry rules, for the different reaction classes. Once rate rules are defined, they allow an easy extension to analogous compounds. In this way, the kinetic mechanism already developed for jet and diesel fuels is extended to the new tar species released by biomasses. Despite unavoidable approximations when the interest is also at the reactor scale, this model is the only one, to our knowledge, able to describe the whole process from biomass to final products, in a predictive and satisfactory way.
\end{abstract}

\title{
Keywords
}

Biomass pyrolysis

Biomass gasification

Fast pyrolysis

Lumped mechanism

Bio-oil

Tars 


\section{Highlights}

A predictive model of biomass pyrolysis, gasification, and combustion is discussed.

A lumped approach to describe biomass pyrolysis products is presented.

The role of successive reactions of tar components is investigated.

Secondary gas phase reactions of released volatiles are analyzed.

Generic rate rules for oxygenated species are highlighted. 


\section{Introduction}

Biomass thermal conversion processes produce heat, electricity, and fuels. Fast pyrolysis is a promising process for the production of renewable bio-oils and chemicals [1]. Bio-oil is a complex mixture of anhydrous sugars, furan derivatives, oxygenated aromatics, and low molecular weight products $[2,3]$. Furthermore, the biomass integrated gasification/combined cycle system is amongst the most promising modern technologies, because of its higher energy efficiency compared to direct combustion [4]. One of the major issues in biomass gasification is to deal with tar formed during the process. Similar to bio-oil, tar is also a complex mixture of condensable hydrocarbons, which includes several oxygen-containing hydrocarbons, along with phenolic and multiple ring aromatic compounds. Tar produced from gasification process mainly contains compounds without oxygen (tertiary tar), as opposite to pyrolysis [5]. The composition of tar and bio-oil is a key factor in assessing pyrolysis and gasification processes. Indeed, it involves hundreds of organic compounds, and it depends on feedstock types, reactor temperature, residence time, and catalytic effects associated to ash. The approximation of tar as a narrow range of components leads to inaccurate predictions of dew point temperature and gasification efficiency. Aiming at improving the understanding of pyrolytic behavior of biomass, Shen et al. [6] recently reviewed biomass fast pyrolysis discussing the yields of liquid and gas products, focusing on the primary and secondary formation pathways of oxygenated compounds. Despite the outstanding importance of developing a reliable reaction model for the design and optimization of biomass pyrolysis and gasification, many difficulties lie behind its formulation. As already emphasized by Carstensen and Dean [7], the complexity and varieties of components found in biomass, together with involved reactions, are the main reasons of these difficulties. Even if the major components of biomass are only three macromolecules such as cellulose, hemicellulose and lignin, their relative compositions 
vary significantly [8], and only cellulose structure is well defined. A further difficulty in developing a detailed kinetic mechanism for biomass pyrolysis is that reactions proceed simultaneously in the condensed and gas phase, therefore their relative role is not well defined.

The kinetic modeling of pyrolysis, gasification, and combustion of biomasses is a very complex multi-component, multi-phase, and multi-scale problem. The strong interactions between chemical kinetics, heat and mass transfer processes involved in the thermal degradation of biomasses make the mathematical modeling difficult. These models require at least the following four features:

- characterization of the biomass in terms of reference components;

- kinetics of devolatilization of reference species in the solid/metaplastic phase;

- kinetics of the gas-solid gasification and combustion of residual char;

- secondary gas-phase reactions of gas and tar species released during devolatilization.

While biomass characterization, together with the corresponding multistep kinetic models of cellulose, hemicellulose, lignins, and extractives has been recently reviewed [8], secondary gas phase reactions of gas and tar released species are discussed in a greater detail in this work. Thus, Section 2 briefly summarizes the characterization method, along with the multistep kinetic scheme of biomass devolatilization. Section 3 analyzes and discusses the secondary reactions of gas and tar species released during biomass pyrolysis. Lastly, comparisons with experimental data highlight the advantages and reliability, as well as the limitations, of the overall kinetic model of pyrolysis, gasification, and combustion of biomasses.

\section{Biomass characterization and multistep kinetic model of devolatilization}

Pyrolysis is the first common step during gasification and combustion processes. Therefore, the characterization of pyrolysis products has attracted great analytical interests [9]. One and twodimensional gas chromatography with flame ionization detector or time-of-flight mass 
spectrometry techniques allow qualitative and quantitative analysis of biofuels composition, thus describing a large portion of bio-oil $[10,11]$. Similarly, the application of tunable synchrotron vacuum ultraviolet photoionization mass spectrometry allows to improve the knowledge of this reaction system [12]. As biomass feedstocks are complex mixtures of several compounds, it is very essential to characterize them in terms of specific number of reference species. While usual characterization methods are limited to the study of cellulose, hemicellulose and lignin components [13-15], detailed characterization was recently extended to triglyceride and tannin species, representatives of extractives [8].

\subsection{Biomass Characterization}

For this modeling work, the reference components of biomasses are cellulose, hemicellulose, lignin, and extractives, which constitute the largest portion of the biomass, often with ash. Biomass pyrolysis products are assumed as a linear combination of the pyrolysis products of these reference compounds, neglecting their possible interactions. When direct information on biochemical composition is not available, cellulose, hemicellulose, lignin, and extractive content is derived through the ultimate biomass composition in terms of $\mathrm{H} / \mathrm{C} / \mathrm{O}[8,15]$. As reference species, together with cellulose and hemicellulose, three different types of lignins, rich in carbon, hydrogen and oxygen, are considered [16]. Finally, triglycerides and condensed tannins are two lumped reference species accounting for hydrophobic and hydrophilic extractives, respectively. Table 1 reports the seven reference species described above. The biomass composition in terms of the seven reference components is calculated from biomass elemental composition by solving the system of atomic mass balances for carbon, hydrogen and oxygen, together with a constraint that defines all fractions to be positive. The following system of linear equations expresses the three atomic balances: 


$$
\begin{aligned}
& C_{B M}=\alpha \cdot C_{R M_{1}}+\beta \cdot C_{R M_{2}}+\gamma \cdot C_{R M_{3}} \\
& H_{B M}=\alpha \cdot H_{R M_{1}}+\beta \cdot H_{R M_{2}}+\gamma \cdot H_{R M_{3}} \\
& O_{B M}=\alpha \cdot O_{R M_{1}}+\beta \cdot O_{R M_{2}}+\gamma \cdot O_{R M_{3}}
\end{aligned}
$$

where $R M_{1}, \mathrm{RM}_{2}$ and $\mathrm{RM} M_{3}$ are the reference mixtures and $\alpha, \beta$ and $\gamma$ their corresponding fractions. Reference mixtures are different combinations of the seven reference species. RM-1 is a mixture of cellulose and hemicellulose, while RM-2 is a mixture of lignins with triglycerides and finally RM3 is again a mixture of lignins with some content of tannins. Further details on this characterization method are reported in Debiagi et al. [8].

\subsection{Multistep Pyrolysis Model}

Although the biomass composition and the thermal treatment conditions can significantly change the product distribution, a similar set of products is always obtained on a qualitative basis. A peculiarity of this model is the detailed characterization of pyrolysis products, which not only includes water vapor and permanent gases $\left(\mathrm{H}_{2}, \mathrm{CO}, \mathrm{CO}_{2}, \mathrm{CH}_{4}\right.$, and $\left.\mathrm{C}_{2} \mathrm{H}_{4}\right)$, several alcohols, aldehydes, and carbonyl compounds, but also different sugars, phenolics and heterocyclic species. At high temperatures, several chemisorbed species contribute to char devolatilization progressively releasing $\mathrm{CO}_{2}, \mathrm{CO}$ and $\mathrm{H}_{2}$.

Each reference component decomposes independently through a multistep, branched mechanism of first-order reactions. Table S1 of the Supplemental Material reports the overall multicomponent and multistep kinetic mechanism of primary biomass pyrolysis. This kinetic mechanism models the formation of intermediate solid and chemisorbed species, together with char, gas, and tar species. 


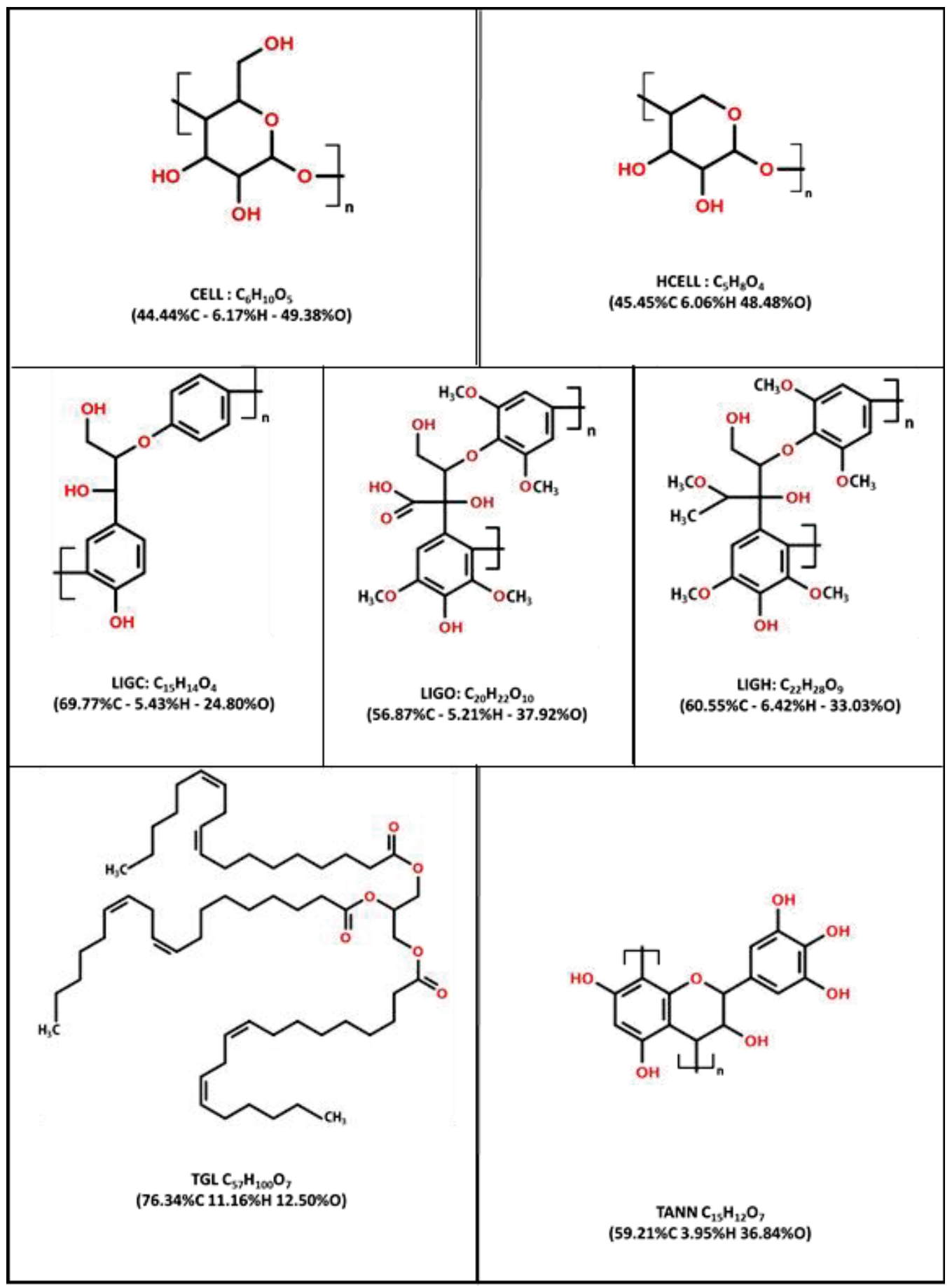

Table 1. Reference species for biomass characterization (after Debiagi et al.[8]).

Both cellulose and hemicellulose are polymeric sugar chains releasing, together with permanent gases, a wide number of hydrocarbon and oxygenated species, including methanol, acetic acid, hydroxy-acetaldehyde, acetone, acetol, furfural, 5-hydroxymethl-furfural, levoglucosan and anydro-sugars [6]. The multistep lignin decomposition mechanism is a simplification of the 
detailed scheme of Faravelli et al. [16]. These reactions are active in a broad temperature range and release phenolic components. Phenol, anisole (metoxy-benzene), 2,6-dimethoxy-phenol, 4-(3hydroxy-1-propenyl)phenol, and 3-(4-hydroxy-3,5-dimethoxy-phenyl) acrylaldehyde are a few lumped and representative species of these compounds. Phenol is also released by the first decomposition step of tannins, while triglycerides (TGL) quickly decompose to a lumped species representative of free fatty acid.

The rates and stoichiometries of these lumped reactions were originally derived from experimental findings [15]. The kinetic model is continuously updated, based on new experimental data and comparisons across a wider range of experimental conditions. Recently, experimental data showed the overshooting of temperature at the center of thick biomass particles, and allowed a better evaluation of the endothermic release of tars and the exothermic charring process [17].

While several detailed kinetic mechanisms are discussed in the literature [18-20], the lumped kinetic scheme discussed and applied in this work is very simplified, aiming at an effective use not only at the particle scale [17], but also at the reactor scale. Computational time limitations are indeed very severe when simulating a gasifier or a biomass combustor at the reactor scale [21, 22]. As a matter of a simple application example, the almond shell analyzed by Caballero et al. [23] is considered. Table 2 shows the ultimate analysis of this biomass sample, together with the corresponding detailed composition in terms of reference species. Figure 1 shows the comparison between model predicted and experimental TG curve. DTG curves of individual reference components are also shown.

Almond Shell 
Ultimate Analysis (wt\% dry and ash free)

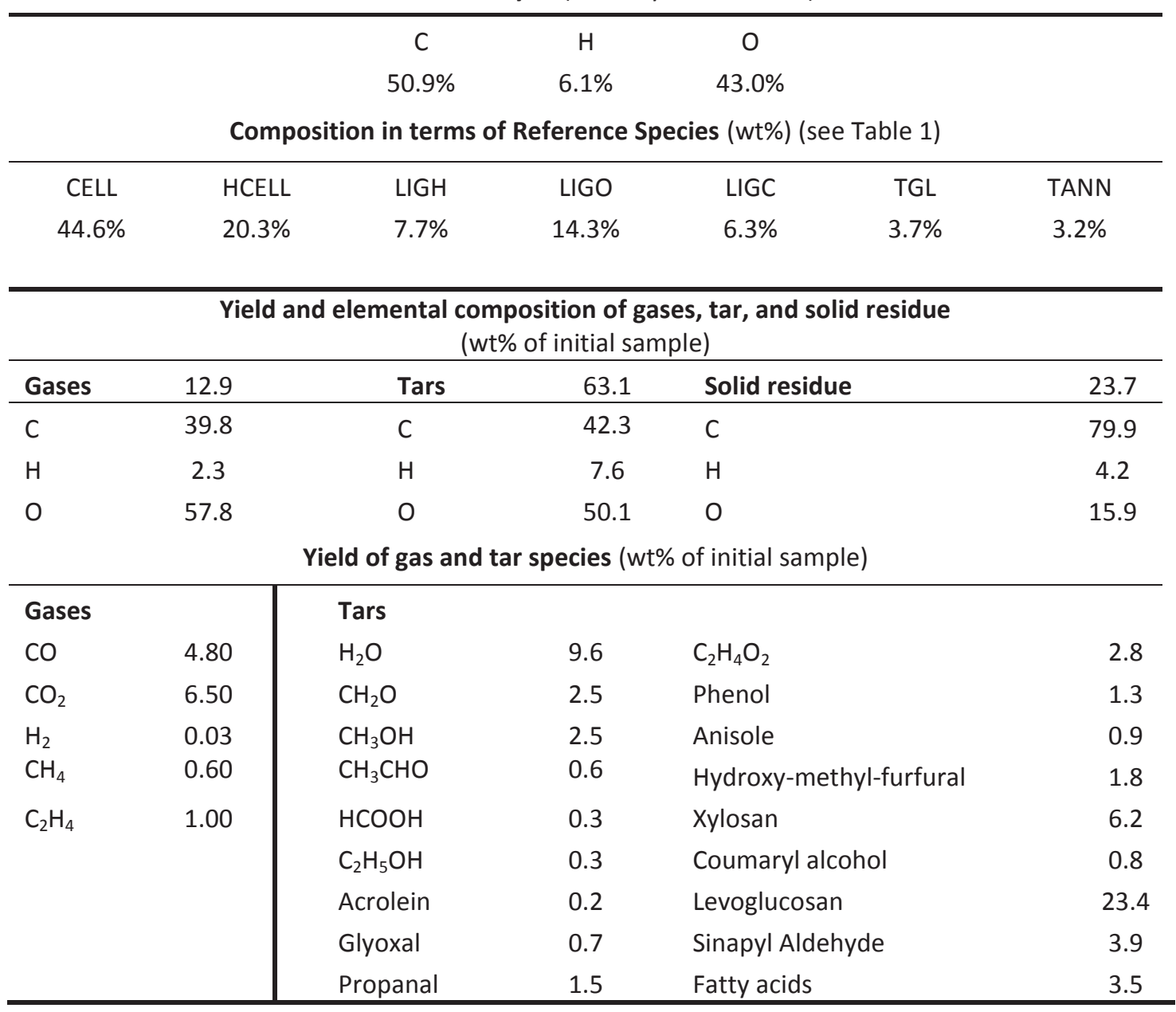

Table 2. Almond Shells [23]. Ultimate analysis, predicted characterization in terms of reference species, and predicted composition of pyrolysis products from TGA of Figure 1.

Table 2 also reports model predictions in terms of detailed composition of released gas and tar species, together with the residual char composition. Experimental data on final products are not available, but model predictions in terms of detailed information on gas, tar, and residual char are reported in order to show how the model is able to describe pyrolysis products. While the primary multi-step kinetic model of biomass pyrolysis was already validated and discussed in recent papers $[8,17]$, the next Section investigates and analyzes the secondary gas phase reactions of the released species. The products reported in Table 2 represent a sample of species whose secondary reactions are analyzed in the next Sections. 


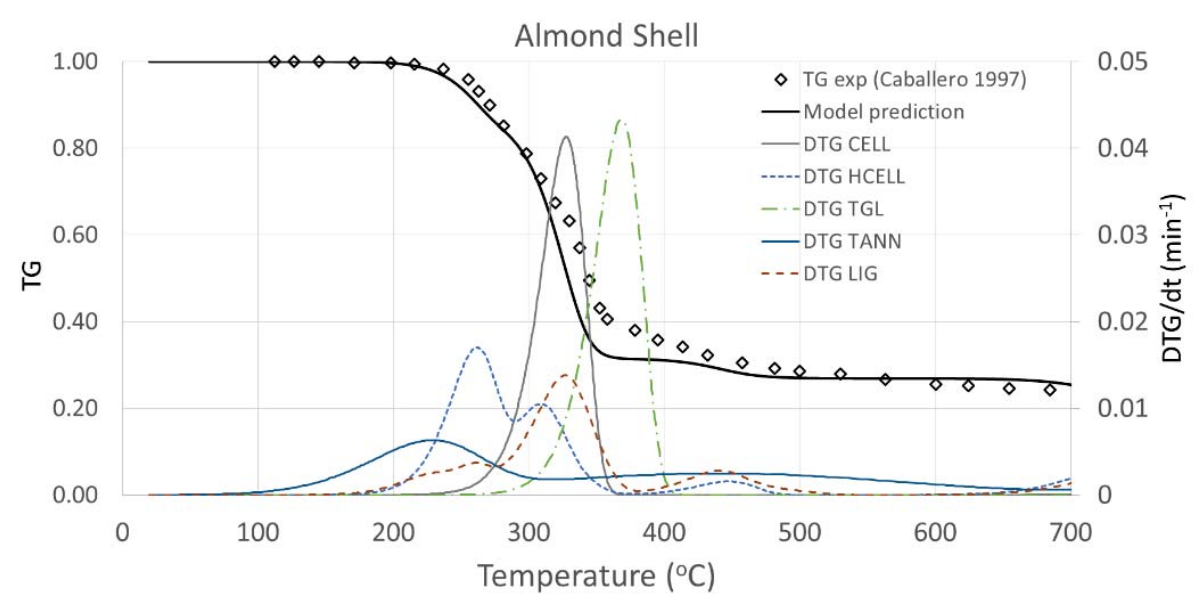

Figure 1. Pyrolysis of almond shell (2 K/min). Comparisons between experimental data (points) [23] and model predictions (lines). DTG curves of individual reference components are also shown.

\section{Kinetic scheme of secondary gas phase reactions.}

During biomass pyrolysis and gasification, primary volatile products are often exposed to high temperatures where gas phase decomposition or combustion reactions can play a significant role. These secondary reactions are a significant part of the overall and comprehensive kinetic model of biomass pyrolysis and oxidation. However, reliable experimental thermochemical data for all these species are not always available [24]. Recently, the decomposition products of lignins, such as monocyclic aromatic compounds with substituent groups like hydroxy, methoxy, formyl, vinyl, and alkyl received particular attention [25]. Carstensen and Dean [7] gave a very significant contribution in defining the secondary gas phase reactions of volatiles released from biomass pyrolysis. From first principle calculations and for a given reaction class, they systematically studied kinetic laws on a series of small reactants and derived generic rate rules, to be extrapolated to all members of the same reaction class. In facts, it is not feasible to perform highlevel calculations for every reaction of this large kinetic model. Namely, they analyzed the $\mathrm{H}$ abstraction and water elimination reactions from alcohols, and the initial decomposition reactions of phenyl ethers. 
The gas-phase kinetic model discussed and applied in this paper was obtained by extending the POLIMI kinetic mechanism for the pyrolysis and oxidation reaction of hydrocarbon and oxygenated species [26].

Table 3 reports a list of relevant oxygenated species released from biomasses, whose primary decomposition reactions are here shortly discussed.

\begin{tabular}{|c|c|c|c|}
\hline Chemical Name & & $\Delta \boldsymbol{H}_{f}$ & $\Delta \boldsymbol{S}_{f}$ \\
\hline Glyoxal & $\mathrm{C}_{2} \mathrm{H}_{2} \mathrm{O}_{2}$ & -50.6 & 65.4 \\
\hline Acetaldehyde & $\mathrm{C}_{2} \mathrm{H}_{4} \mathrm{O}$ & -39.5 & 63.0 \\
\hline $\begin{array}{l}\text { Hydroxy- } \\
\text { acetaldehyde }\end{array}$ & $\mathrm{C}_{2} \mathrm{H}_{4} \mathrm{O}_{2}$ & -73.5 & 73.5 \\
\hline Ethyleneglycol & $\mathrm{C}_{2} \mathrm{H}_{6} \mathrm{O}_{2}$ & -92.0 & 76.3 \\
\hline $\begin{array}{l}\text { Hydroxyl-oxo- } \\
\text { propanal }\end{array}$ & $\mathrm{C}_{2} \mathrm{H}_{4} \mathrm{O}_{3}$ & -102.7 & 88.4 \\
\hline Acrolein & $\mathrm{C}_{3} \mathrm{H}_{4} \mathrm{O}$ & -20.3 & 67.4 \\
\hline Propanedial & $\mathrm{C}_{3} \mathrm{H}_{4} \mathrm{O}_{2}$ & -62.4 & 73.7 \\
\hline Propanal & $\mathrm{C}_{3} \mathrm{H}_{6} \mathrm{O}$ & -45.3 & 72.8 \\
\hline 1-propanol & $\mathrm{C}_{3} \mathrm{H}_{8} \mathrm{O}$ & -60.9 & 76.4 \\
\hline 2-propanol & $\mathrm{C}_{3} \mathrm{H}_{8} \mathrm{O}$ & -65.5 & 74.5 \\
\hline Acetol & $\mathrm{C}_{3} \mathrm{H}_{6} \mathrm{O}_{2}$ & -87.4 & 80.6 \\
\hline 3-hydroxypropanal & $\mathrm{C}_{3} \mathrm{H}_{6} \mathrm{O}_{2}$ & -80.3 & 83.3 \\
\hline 1,3-propanediol & $\mathrm{C}_{3} \mathrm{H}_{8} \mathrm{O}_{2}$ & -45.5 & 86.0 \\
\hline Glycerol & $\mathrm{C}_{3} \mathrm{H}_{8} \mathrm{O}_{3}$ & -137.1 & 95.8 \\
\hline Furan & $\mathrm{C}_{4} \mathrm{H}_{4} \mathrm{O}$ & -10.2 & 60.2 \\
\hline Butanedione & $\mathrm{C}_{4} \mathrm{H}_{6} \mathrm{O}_{2}$ & -78.4 & 84.2 \\
\hline C4 O-heterocycles & $\mathrm{C}_{4} \mathrm{H}_{8} \mathrm{O}$ & -27.7 & 73.6 \\
\hline Furfural & $\mathrm{C}_{5} \mathrm{H}_{4} \mathrm{O}_{2}$ & -36.1 & 77.8 \\
\hline Xylosan & $\mathrm{C}_{5} \mathrm{H}_{8} \mathrm{O}_{4}$ & -151.6 & 104.8 \\
\hline Phenol & $\mathrm{C}_{6} \mathrm{H}_{6} \mathrm{O}$ & -23.0 & 75.3 \\
\hline $\begin{array}{l}\text { Hydroxymethyl- } \\
\text { furfural }\end{array}$ & $\mathrm{C}_{6} \mathrm{H}_{6} \mathrm{O}_{3}$ & -79.8 & 98.2 \\
\hline Levoglucosan & $\mathrm{C}_{6} \mathrm{H}_{10} \mathrm{O}_{5}$ & -200.9 & 113.5 \\
\hline Anisole & $\mathrm{C}_{7} \mathrm{H}_{8} \mathrm{O}$ & -17.1 & 84.0 \\
\hline Syringol & $\mathrm{C}_{8} \mathrm{H}_{10} \mathrm{O}_{3}$ & -95.3 & 111.0 \\
\hline Coumaryl alcohol & $\mathrm{C}_{9} \mathrm{H}_{10} \mathrm{O}_{2}$ & -49.2 & 109.0 \\
\hline Sinapyl aldehyde & $\mathrm{C}_{11} \mathrm{H}_{12} \mathrm{O}_{4}$ & -0.3 & 186.7 \\
\hline
\end{tabular}

Table 3. Formation enthalpy $\Delta H_{f, 298}[\mathrm{kcal} / \mathrm{mol}]$ and formation entropy $\Delta S_{f, 298}[\mathrm{cal} / \mathrm{mol} / \mathrm{K}]$ of major oxygenated species released from biomasses and involved in secondary gas phase reactions.

Due to their modular structure, the extension of detailed kinetic mechanisms to the new species requires to include their primary propagation reactions. Typically, the reaction classes to be 
included are initiation, $\mathrm{H}$-abstraction and addition reactions, together with molecular and successive radical decompositions until the formation of intermediate products already accounted for in the original kinetic scheme. The complete and extended kinetic mechanism, as well as thermodynamic and transport properties, is reported as Supplemental Material and is also available at http://creckmodeling.chem.polimi.it/. Here, we simply and shortly summarize and revise the general rules applied in developing and extending the whole kinetic mechanism to the new species reported in Table 3.

\subsection{Chain initiation and $\mathrm{H}$-abstraction reactions}

Since the pioneering developments of detailed oxidation mechanisms of hydrocarbon fuels [2730], the definition of different reaction classes with well-defined rate rules is the first step towards the computer-aided generation of complex kinetic mechanisms of large hydrocarbon and oxygenated fuels. Several reaction classes, together with physically consistent rate rules and kinetic parameters, were established, and these reaction classes and rate rules are continuously completed and revised based on new experimental and theoretical data [31, 32].

Unimolecular initiation reactions activate the chain radical propagation process, breaking chemical bonds and forming two radicals:

$$
R-R^{\prime} \leftrightarrow R \bullet+R^{\prime} \bullet
$$

Rate constants strongly depend on the dissociation energy of the bond involved in these reactions. $\mathrm{H}$-abstraction reactions play a key role in determining the system reactivity both in pyrolysis and oxidation conditions. It is generally accepted that the rate constant of the generic reaction:

$$
\mathrm{R} \bullet+R^{\prime} H \leftrightarrow R^{\prime} \bullet+R-H
$$

depends on the properties of the abstracting radical $\left(R_{\bullet}\right)$ and the type of hydrogen to be abstracted [33-35]. 
The type of $\mathrm{H}$-atom mainly refers to the strength of the corresponding $\mathrm{C}-\mathrm{H}$ bond. Then, prior to the discussion of the rate rules, it is convenient to analyze the differences in the $\mathrm{C}-\mathrm{H}$ and $\mathrm{O}-\mathrm{H}$ bond dissociation energies (BDEs) of different hydrocarbon and oxygenated species. Similarly, the BDEs of the $\mathrm{C}-\mathrm{C}$ and $\mathrm{C}-\mathrm{O}$ bonds are useful to investigate the relative importance of the unimolecular initiation reactions.

\subsubsection{Bond dissociation energies (BDE) of $C_{4}$ hydrocarbon and oxygenated species}

The G4 computational method developed by Curtiss et al. [36] as implemented in the Gaussian-09 suite [37] was used to calculate $\mathrm{C}-\mathrm{H}$ and $\mathrm{C}-\mathrm{C}$ (as well as $\mathrm{O}-\mathrm{H}$ and $\mathrm{C}-\mathrm{O}$ ) bond dissociation energies. According to the corresponding elementary decomposition reactions, the BDEs are determined at $298 \mathrm{~K}$ as the difference in the G4-energy between the reactant and the formed decomposition radicals. Table 4 summarizes the BDEs for $n$-butane, iso-butane, 1- and 2-butene, together with $n$ butanol and $n$-butanal as reference oxygenated species. The calculated BDEs are in good agreement with the corresponding ones estimated with the MRACPF2 method by Oyeyemi et al. [38]. Further details on these BDE calculations are reported by Pelucchi et al. [39]. 


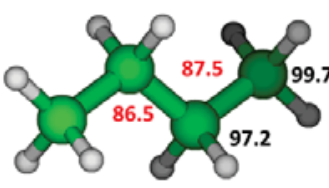

n-butane

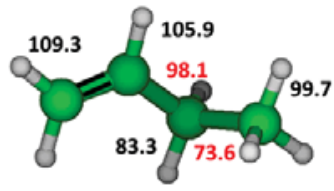

1-butene

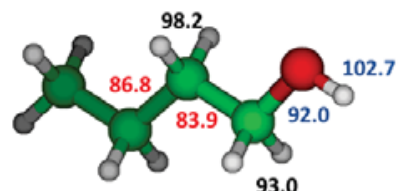

1-butanol

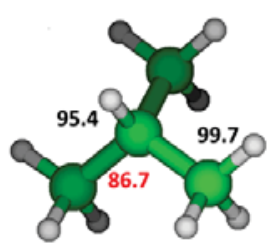

iso-butane

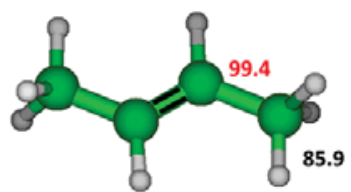

2-butene

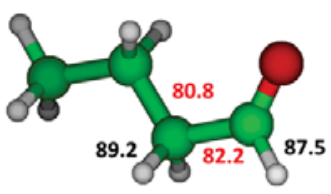

1-butanal

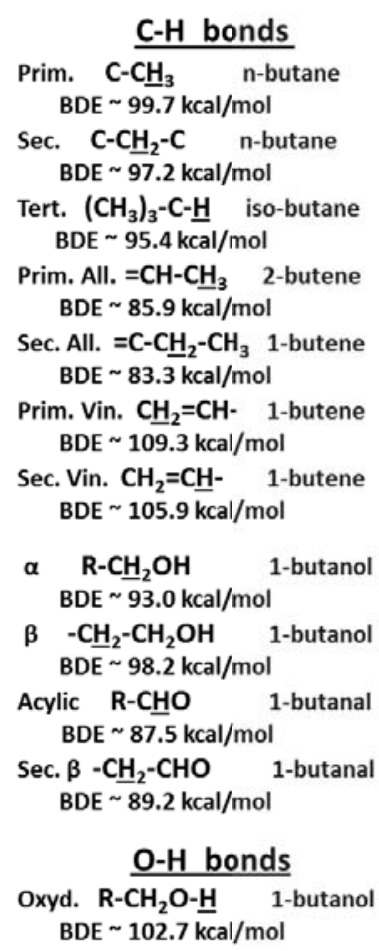

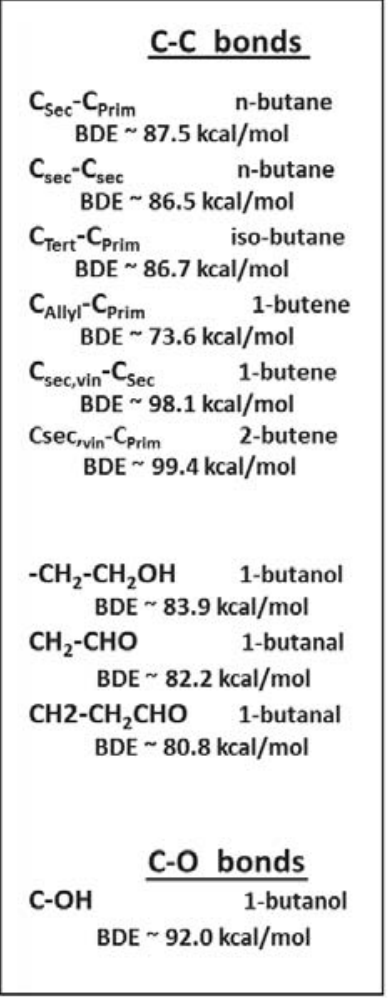

Table 4. Bond dissociation energies (BDE) of $\mathrm{C}_{4}$ hydrocarbon and oxygenated species. $\mathrm{C}-\mathrm{H}$ (black), $\mathrm{C}-\mathrm{C}$ (red), and $\mathrm{C}-\mathrm{O} \& \mathrm{O}-\mathrm{H}$ (blu) bond dissociation energies (kcal/mol) calculated at G4 level (298 K)[34]

\subsubsection{H-abstraction reactions}

The dominant reactive radicals in pyrolysis and oxidation conditions are $\mathrm{H}, \mathrm{OH}$ and $\mathrm{CH}_{3}$, which abstract $\mathrm{H}$-atoms to form $\mathrm{H}_{2}, \mathrm{H}_{2} \mathrm{O}$ and methane. $\mathrm{H}$-abstraction reactions from pure hydrocarbons have shown that individual rate constants are obtained, with good accuracy, by generic rate rules for individual rate expressions $[7,33,35,40]$. Due to the different $\mathrm{C}-\mathrm{H}$ BDEs, the activation energy required by methyl and alkyl radicals for the abstraction of a secondary $\mathrm{H}$-atom in an alkane is $\sim 2.5$ $\mathrm{kcal} / \mathrm{mol}$ lower with respect to the corresponding energy to abstract a primary $\mathrm{H}$-atom. Again, by comparing primary and tertiary $\mathrm{H}$-atoms in iso-butane, the tertiary $\mathrm{H}$-atom abstraction is favored by $\sim 4 \mathrm{kcal} / \mathrm{mol}$. Whenever direct and more accurate kinetic parameters were not available, these energy corrections and simple rules have been successfully applied in the development of 
pyrolysis and oxidation mechanisms [26]. Figure 2 shows the H-abstraction rates of primary, secondary, and tertiary $\mathrm{H}$-atoms by $\mathrm{H} \bullet, \bullet \mathrm{OH}$ and $\bullet \mathrm{CH}_{3}$ radicals. Accordingly, with the large $\mathrm{BDE}$ differences of $\mathrm{C}-\mathrm{H}$ bonds, $\mathrm{H}$-abstractions on alkenes indicate that $\mathrm{H}$-atoms in allyl and vinyl position become more and less reactive, respectively. These rate values are also reported in Figure 2, with respect to the secondary $\mathrm{H}$-atoms. These simple rules allow the automatic generation of the $\mathrm{H}$-abstraction reactions for the whole class of alkanes and alkenes, properly accounting for the individual reactivity of the different $\mathrm{H}$-atoms.

The same approach is applied to alcohols and aldehydes, and more in general to the oxygenated tar species, where the presence of oxygen atom largely influences the BDE of adjacent $\mathrm{C}-\mathrm{H}$ bonds, as shown in Table 4. Previous kinetic studies on alcohol fuels[41, 42] clearly highlighted that the rate of $\mathrm{H}$-abstraction from the hydroxyl group $(\mathrm{ROH})$ by a generic radical is even lower than the corresponding abstraction rate of a single primary $\mathrm{H}$-atom. This is fully consistent with the BDE of the RO-H bond in $\mathrm{n}$-butanol, which is higher than the BDE of the primary $\mathrm{H}$ atoms in alkanes. Moreover, the nature of the alkyl R-group does not significantly affect these values. Successive decomposition reactions of alkoxyl radicals are discussed by Curran[43].
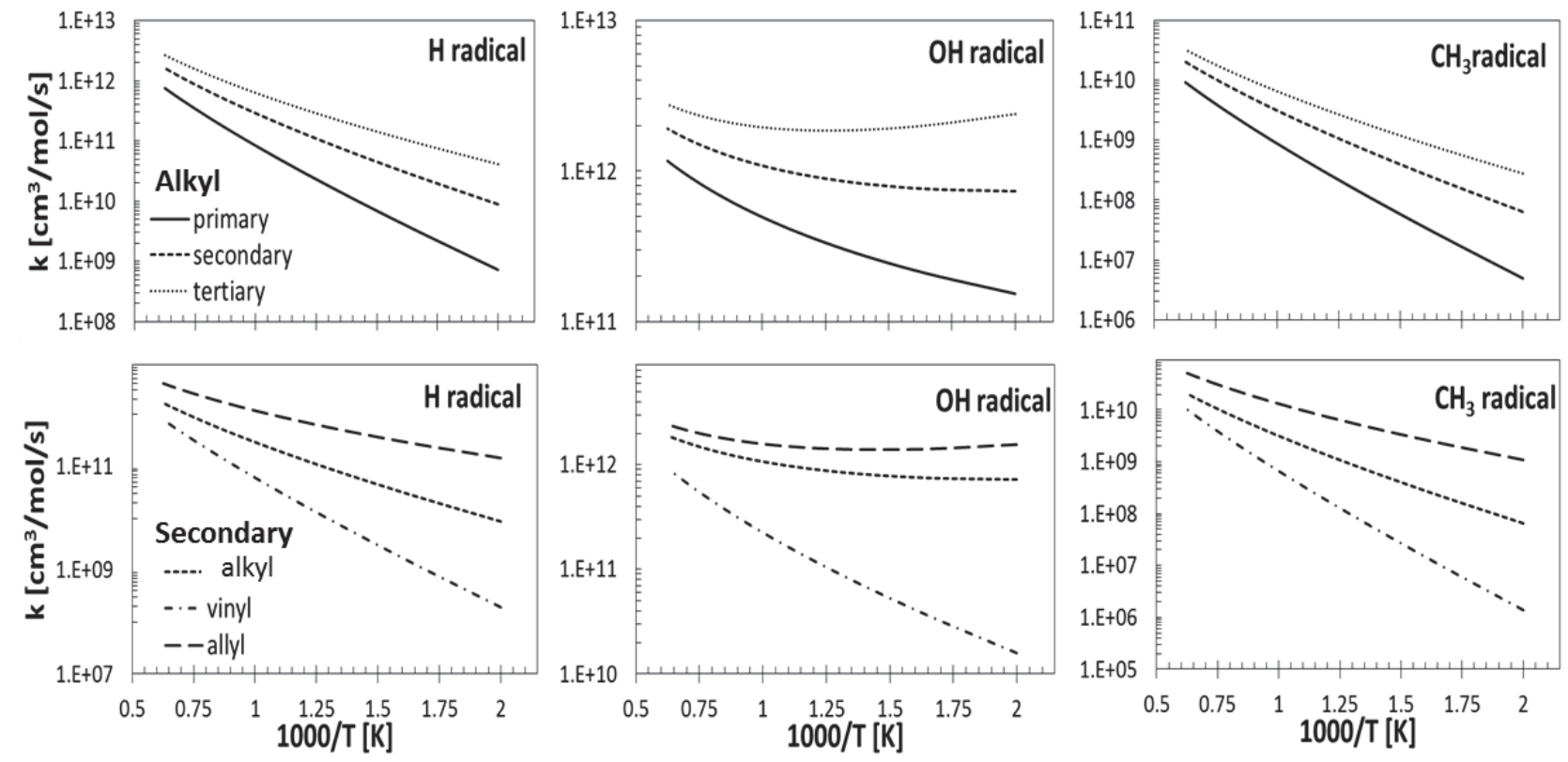
Figure 2: H-abstraction reactions. Calculated rate constants (per H-atom) for simple primary, secondary, tertiary H-atoms (top) and for secondary H-atoms in alkyl, vinyl, and allyl positions (bottom).

$\mathrm{H}$-abstractions from $\mathrm{C}-\mathrm{H}$ bonds in the $\alpha$-position to the hydroxyl group strongly depend on the type of the $\mathrm{H}$-atom to be removed. Rate parameters of the abstraction of $\alpha \mathrm{H}$-atoms, such as those of ethanol, n-propanol, 1-butanol, and iso-butanol, are 1.5 faster than the corresponding rate parameters of abstraction of secondary $\mathrm{H}$-atoms in alkanes (Figure 2). Similarly, the abstraction parameters of $\alpha \mathrm{H}$-atoms, such those of iso-propanol and 2-butanol, are $\sim 1.5$ times the corresponding ones of tertiary $\mathrm{H}$-atoms. According to Carstensen and Dean [7], the influence of the $\mathrm{OH}$ group on the reactivity of $\mathrm{C}-\mathrm{H}$ bonds practically vanishes at the $\beta$-position. From this site on, the rate constants of the different $\mathrm{H}$-atoms follow the reference values of $\mathrm{H}$-atoms in alkanes. 
Due to the low BDE of the $\mathrm{C}-\mathrm{H}$ bond in the carbonyl group of aldehydes, the removal of the acylic $\mathrm{H}$-atom is highly favored. Based on the analysis of these reactions on formaldehyde, acetaldehyde, and heavier aldehydes[44], the following rate parameters for abstraction of the acylic $\mathrm{H}$-atom by $\mathrm{H}, \mathrm{OH}$ and $\mathrm{CH}_{3}$ radicals are assumed:

$$
\begin{array}{ll}
k^{\mathrm{H}}=2.510^{14} \exp (-6360 / \mathrm{RT}) & {\left[\mathrm{cm}^{3} / \mathrm{s} / \mathrm{mol}\right]} \\
k^{\mathrm{OH}}=2.010^{13} \exp (-630 / \mathrm{RT}) & {\left[\mathrm{cm}^{3} / \mathrm{s} / \mathrm{mol}\right]} \\
\mathrm{k}^{\mathrm{CH} 3}=7.010^{11} \exp (-7235 / \mathrm{RT}) & {\left[\mathrm{cm}^{3} / \mathrm{s} / \mathrm{mol}\right]}
\end{array}
$$

The $\mathrm{H}$-abstraction rates from $\mathrm{C}-\mathrm{H}$ sites in $\alpha$-position to the carbonyl group again are enhanced by a factor 1.25 with respect to the corresponding $\mathrm{C}-\mathrm{H}$ sites in alkanes. All these generic rate rules are useful to create a first reasonable set of rate parameters. More accurate evaluations could be of course required when rate and sensitivity analyses identify sensitive reactions [7].

\subsubsection{Unimolecular initiation reactions}

$\mathrm{C}-\mathrm{C}$ and $\mathrm{C}-\mathrm{H}$ bond dissociation energies are very useful to directly estimate the unimolecular initiation reactions. These reactions are always the important chain initiation steps even if their direct contributions to fuel consumption are only present at relatively high temperatures [45]. Assuming the rate constant for the reverse recombination reactions, from the microscopic reversibility principle it is practical to evaluate the rate constant of initiation reactions. If the activation energy of the recombination reactions is zero, the BDEs directly become the activation energy of the corresponding unimolecular dissociation reaction. Of course, the favored initiation reactions are the ones involving the lower activation energies, i.e. the lower BDEs. The difference between the $\mathrm{BDE}$ of 1 -butene and $\mathrm{n}$-butane to form the resonant allyl radical and two ethyl radicals, respectively, explains the different activation energy of these two initiation reactions:

$$
\begin{aligned}
& \mathrm{n}-\mathrm{C}_{4} \mathrm{H}_{10} \leftrightarrow \cdot \mathrm{C}_{2} \mathrm{H}_{5}+\bullet \mathrm{C}_{2} \mathrm{H}_{5} \quad \mathrm{k}=10^{16 .} \exp (-82000 / \mathrm{RT}) \quad\left[\mathrm{s}^{-1}\right] \\
& 1-\mathrm{C}_{4} \mathrm{H}_{8} \leftrightarrow \cdot \mathrm{C}_{3} \mathrm{H}_{5}+\cdot \mathrm{CH}_{3} \quad \mathrm{k}=10^{16} \exp (-73000 / \mathrm{RT}) \quad\left[\mathrm{s}^{-1}\right]
\end{aligned}
$$


Similarly, the activation energies of initiation reactions of butanal [44]:

$$
\begin{array}{lrr}
\mathrm{CH}_{3} \mathrm{CH}_{2} \mathrm{CH}_{2} \mathrm{CHO} \leftrightarrow \bullet \mathrm{CH}_{3}+\bullet \mathrm{CH}_{2} \mathrm{CH}_{2} \mathrm{CHO} & \mathrm{k}=10^{16.3} \exp (-86000 / \mathrm{RT}) & {\left[\mathrm{s}^{-1}\right]} \\
\mathrm{CH}_{3} \mathrm{CH}_{2} \mathrm{CH}_{2} \mathrm{CHO} \leftrightarrow \bullet \mathrm{C}_{2} \mathrm{H}_{5}+\bullet \mathrm{CH}_{2} \mathrm{CHO} & \mathrm{k}=10^{16.0} \exp (-79000 / \mathrm{RT}) & {\left[\mathrm{s}^{-1}\right]} \\
\mathrm{CH}_{3} \mathrm{CH}_{2} \mathrm{CH}_{2} \mathrm{CHO} \leftrightarrow \bullet \mathrm{C}_{3} \mathrm{H}_{7}+\bullet \mathrm{CHO} & \mathrm{k}=10^{16.0} \exp (-80000 / \mathrm{RT}) & {\left[\mathrm{s}^{-1}\right]}
\end{array}
$$

reflect the different dissociation energies of the corresponding bonds.

The initiation reactions, which cleavage $\mathrm{C}-\mathrm{H}$ bonds, are mainly important in the reverse direction as sinks of $\mathrm{H}$ atoms, because of their very high BDEs.

\subsection{Carbohydrates and water elimination reactions}

The previous already mentioned kinetic studies of alcohol fuels highlighted the importance of the following molecular water elimination reactions:

$$
\begin{array}{lll}
1-\mathrm{C}_{4} \mathrm{H}_{9} \mathrm{OH} \leftrightarrow 1-\mathrm{C}_{4} \mathrm{H}_{8}+\mathrm{H}_{2} \mathrm{O} & \mathrm{k}=10^{14} \exp (-67600 / \mathrm{RT}) & {\left[\mathrm{s}^{-1}\right]} \\
2-\mathrm{C}_{4} \mathrm{H}_{9} \mathrm{OH} \leftrightarrow 2-\mathrm{C}_{4} \mathrm{H}_{8}+\mathrm{H}_{2} \mathrm{O} & \mathrm{k}=10^{14} \exp (-66100 / \mathrm{RT}) & {\left[\mathrm{s}^{-1}\right]} \\
2-\mathrm{C}_{4} \mathrm{H}_{9} \mathrm{OH} \leftrightarrow 1-\mathrm{C}_{4} \mathrm{H}_{8}+\mathrm{H}_{2} \mathrm{O} & \mathrm{k}=1.510^{14} \exp (-67100 / R T) & {\left[\mathrm{s}^{-1}\right]} \\
\text { iso- } \mathrm{C}_{4} \mathrm{H}_{9} \mathrm{OH} \leftrightarrow \text { iso }-\mathrm{C}_{4} \mathrm{H}_{8}+\mathrm{H}_{2} \mathrm{O} & \mathrm{k}=5.010^{13} \exp (-65600 / R T) & {\left[\mathrm{s}^{-1}\right]} \\
\text { tert }-\mathrm{C}_{4} \mathrm{H}_{9} \mathrm{OH} \leftrightarrow \text { iso- } \mathrm{C}_{4} \mathrm{H}_{8}+\mathrm{H}_{2} \mathrm{O} & \mathrm{k}=4.510^{14} \exp (-65100 / \mathrm{RT}) & {\left[\mathrm{s}^{-1}\right]}
\end{array}
$$

These kinetic parameters, well confirmed by theoretical calculations [46] as well by the recent review of Sarathy et al. [47], show that reference rate values for this reaction class are only slightly affected by the position of the $\mathrm{OH}$ group inside the carbon skeleton. While the different alcohol has little impact on reference rate constant, large deviations are observed for substituted aldehydes, when water elimination reactions yield products with conjugated double bonds. Figure 3 clearly shows two successive molecular dehydration reactions in glycerol pyrolysis [48]. 


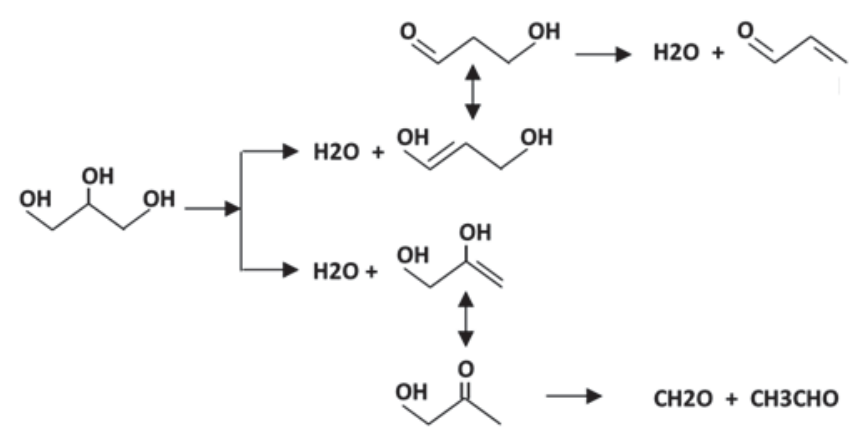

Figure 3. Water elimination reactions in glycerol pyrolysis.

The first dehydration reaction can either form prop-1-ene-1,3-diol or prop-1-ene-2,3-diol. Ketoenol tautomerism transforms prop-1-ene-1,3-diol into 3-hydroxypropanal, which rapidly forms acrolein through a second dehydration reaction. The aldehyde moiety strongly influences the reactivity by stabilizing the transition state and the products [7]. This stabilizing effect is accounted for with a reduction of the activation energy of more than $10 \mathrm{kcal} / \mathrm{mol}$.

These reaction rates also dominate the first molecular dehydration with/without ring opening of levoglucosan and xylan components, as well as successive dehydration reactions. Mayes et al. [49] presented a very comprehensive study of elementary mechanisms of unimolecular glucose 1,2dehydration reactions and conversion to the pyranose and furanose forms of levoglucosan, together with the glucose pyrolysis to form 5-hydroxy-methyl-furfural $\left(\mathrm{C}_{6} \mathrm{H}_{6} \mathrm{O}_{3}\right.$ : $\left.\mathrm{HMFU}\right)$. The comparison of different dehydration reactions emphasizes the importance of adjacent functional groups and stereochemistry in determining reaction kinetics. Successive decomposition reactions of 5-hydroxymethyl-furfural form furfuryl-alcohol and $\left(\mathrm{C}_{5} \mathrm{H}_{6} \mathrm{O}_{2}\right)$ furfural $\left(\mathrm{C}_{5} \mathrm{H}_{4} \mathrm{O}_{2}\right)$ [6].

Along with the molecular dehydration, the unimolecular initiation and $\mathrm{H}$-abstraction reactions are also considered for these species. Intermediate radicals can then decompose forming the major intermediates, such as formaldehyde, hydroxyl-acetaldehyde, glyoxal, acetol, and other small- 
oxygenated components. Retro-Diels Alder reactions constitute a parallel molecular path to form $\mathrm{C}_{2}-\mathrm{C}_{4}$ oxygenated species [7]. Aromatic and phenolic species and successive reactions

The first decomposition of lignin releases aromatic and phenolic components. Saggese et al. [50, 51] recently discussed the intermediate and high temperature reactions of benzene with the successive paths to form polycyclic aromatic hydrocarbons (PAH) and soot. While the reactions of PAH aromatics (involving naphthalene, acenaphthylene, phenanthrene, pyrene, up to $\mathrm{C}_{20}$ aromatics) are considered in the gas-phase kinetic scheme reported in the Supplemental Material, the soot kinetic model [50] contains the successive reactions of PAH species to form carbon particles up 50-100 $\mathrm{nm}$.

Kinetic studies on phenol, cresol, and anisole chemistry show the importance of CO elimination from unsubstituted and substituted phenoxy radicals. The reference reaction rate raises from the following reaction:

$$
\mathrm{C}_{6} \mathrm{H}_{5} \mathrm{O} \bullet \rightarrow \mathrm{cyC}_{5} \mathrm{H}_{5} \bullet+\mathrm{CO} \quad \mathrm{k}=5.10^{11} \exp (-43920 / \mathrm{RT}) \quad\left[\mathrm{s}^{-1}\right]
$$

Reactions of phenoxy-substituted species to form CO and cyclopentadienyl radicals were also revised by Carstensen and Dean [35]. Successive reactions of cyclopentadienyl radicals are responsible for the formation of naphthalene and heavier PAHs [52]. While phenol and cresol were investigated for their interest in combustion systems, anisole $\left(\mathrm{C}_{6} \mathrm{H}_{5} \mathrm{OCH}_{3}\right)$ was mainly studied as the simplest surrogate for primary tar from lignin pyrolysis [53, 54].

Chain initiation reactions of aromatic species containing a methoxy group $\left(-\mathrm{OCH}_{3}\right)$ involve the breaking of the weak C-O bond in the methoxy group (BDE $63.2 \mathrm{kcal} / \mathrm{mol}$ ) [55]. Indicating with $\mathrm{Ph}$ the unsubstituted or substituted phenyl groups, the following reference reaction is assumed for the formation of phenoxy or phenoxy like radicals $(\mathrm{Ph}-\mathrm{O})$ :

$$
\mathrm{Ph}-\mathrm{OCH}_{3} \rightarrow \mathrm{Ph}-\mathrm{O} \bullet+\cdot \mathrm{CH}_{3} \quad \mathrm{k}=3.10^{15} \exp (-63200 / \mathrm{RT}) \quad\left[\mathrm{s}^{-1}\right]
$$


The same rate rules are assumed when replacing $\mathrm{CH}_{3}$ with a different alkyl radical. Together with the $\mathrm{H}$-abstractions on side groups of aromatic species, the following rates are selected as reference values for the ipso-addition reactions on generic aromatic species:

$$
\begin{array}{lll}
\mathrm{H} \bullet+\text { Toluene } \rightarrow \text { Benzene }+\bullet \mathrm{CH}_{3} & \mathrm{k}=1.210^{13} \exp (-5100 / \mathrm{RT}) & {\left[\mathrm{cm}^{3} / \mathrm{s} / \mathrm{mol}\right]} \\
\mathrm{H} \bullet+\text { Anisole } \rightarrow \text { Phenol }+\bullet \mathrm{CH}_{3} & \mathrm{k}=1.10^{13} \exp (-6000 / \mathrm{RT}) & {\left[\mathrm{cm}^{3} / \mathrm{s} / \mathrm{mol}\right]} \\
\mathrm{H} \bullet+\text { Phenol } \rightarrow \text { Benzene }+\bullet \mathrm{OH} & \mathrm{k}=1.210^{13} \exp (-6000 / \mathrm{RT}) & {\left[\mathrm{cm}^{3} / \mathrm{s} / \mathrm{mol}\right]} \\
\mathrm{H} \bullet+\text { Anisole } \rightarrow \text { Benzene }+\bullet \mathrm{OCH}_{3} & \mathrm{k}=1.10^{13} \exp (-8000 / \mathrm{RT}) & {\left[\mathrm{cm}^{3} / \mathrm{s} / \mathrm{mol}\right]} \\
\bullet \mathrm{OH}+\text { Toluene } \rightarrow \text { Cresol }+\mathrm{H} \bullet & \mathrm{k}=1.110^{12} \exp (-11000 / \mathrm{RT}) & {\left[\mathrm{cm}^{3} / \mathrm{s} / \mathrm{mol}\right]} \\
\bullet \mathrm{OH}+\text { Toluene } \rightarrow \text { Phenol }+\bullet \mathrm{CH}_{3} & \mathrm{k}=4.410^{12} \exp (-6700 / \mathrm{RT}) & {\left[\mathrm{cm}^{3} / \mathrm{s} / \mathrm{mol}\right]} \\
\bullet \mathrm{CH}_{3}+\text { Phenol } \rightarrow \text { Cresol }+\mathrm{H} \bullet & \mathrm{k}=1.310^{12} \exp (-16200 / \mathrm{RT}) & {\left[\mathrm{cm}^{3} / \mathrm{s} / \mathrm{mol}\right]} \\
\bullet \mathrm{CH}_{3}+\text { Phenol } \rightarrow \text { Toluene }+\mathrm{OH} & \mathrm{k}=1.10^{12} \exp (-15000 / \mathrm{RT}) & {\left[\mathrm{cm}^{3} / \mathrm{s} / \mathrm{mol}\right]}
\end{array}
$$

All these reactions progressively convert the aromatic and phenolic species and their rate values mainly derive from the kinetic studies of pyrolysis and oxidation of anisole and phenol $[51,53]$. More recently, anisole pyrolysis and oxidation were studied by Nowakowska et al. [54] in a jet-stirred reactor under diluted conditions at 673-1173 K, residence time $2 \mathrm{~s}$, and $106.7 \mathrm{kPa}$. Figure 4 shows selected comparisons between these experimental data and the predictions of the proposed model.

Saggese et al. [51] observed a similar satisfactory agreement when discussing and comparing model predictions with experimental data from the pyrolysis and oxidation of phenol in flow reactors. 

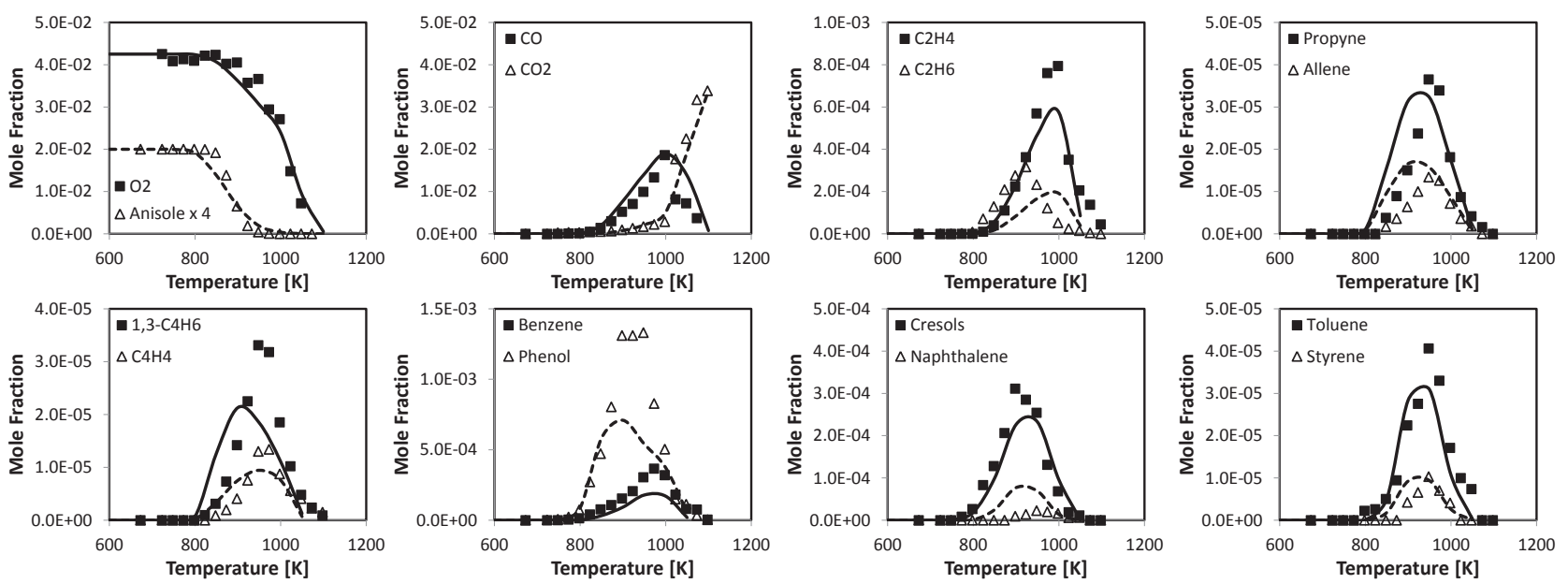

Figure 4. Mole fraction profiles of major species during the stoichiometric oxidation of anisole at residence time $2 \mathrm{~s}$ and $106.7 \mathrm{kPa}$. Symbols refer to experiments [54] and lines to model predictions.

\section{Comparisons with experimental data}

Since the previously referred papers $[15,17]$, several experimental data at particle and reactor scale were used to develop and validate the overall biomass pyrolysis model, including the secondary gas-phase reactions. Fast and slow pyrolysis [56], severe gasification in drop tube [57], combustion in a traveling grate [58] are only a few examples of the analyzed experimental conditions. Here the comparisons are limited to recent experimental data, which give more attention to the secondary gas phase reactions of released species. Norinaga et al. [59] and Yang et al. [60] studied the kinetics of secondary vapor-phase decomposition of volatiles generated from the fast pyrolysis of cellulose and lignin in a two-stage tubular reactor, while minimizing volatile-char interactions. Avicel cellulose with particle sizes ranging from 74 to $105 \mu \mathrm{m}$ was used by Norinaga, while the lignin samples used by Yang had particle sizes in the range of $75-150 \mu m$. These particle sizes allow to neglect mass and heat transfer limitations. Norinaga et al. [59] provided experimental data of tar and gas compositions during secondary pyrolysis of cellulose volatiles, at temperatures of 700 and $800{ }^{\circ} \mathrm{C}$. The most abundant product is always $\mathrm{CO}$, along with major species such as $\mathrm{H}_{2} \mathrm{O}, \mathrm{CH}_{4}$, and $\mathrm{H}_{2}$. These data are useful not only to verify the primary 
released species, but mainly to analyze the effect of the secondary gas phase reactions studied with residence times up to 6 s. Figure 5 shows a satisfactory comparison between experimental data and model predictions in terms of time evolution of major pyrolysis products.
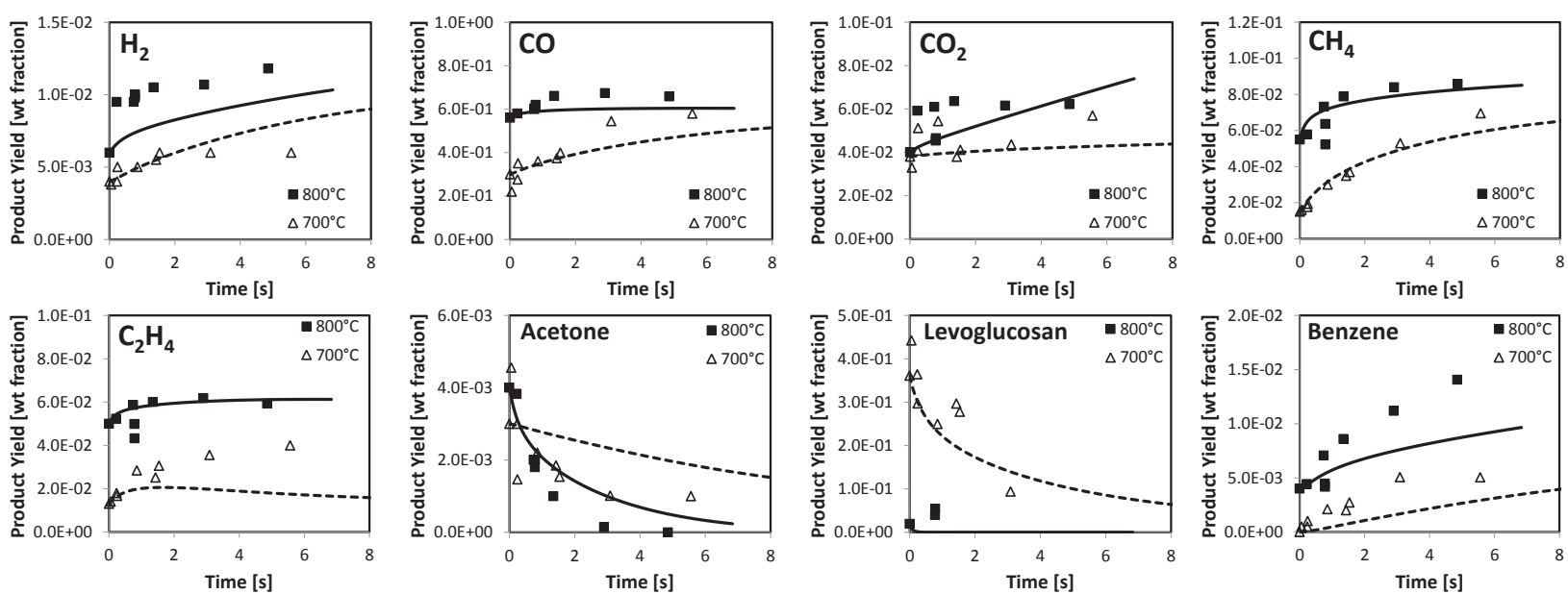

Figure 5. Effect of secondary gas-phase reactions on volatile species released from cellulose pyrolysis at $700^{\circ} \mathrm{C}$ and $800^{\circ} \mathrm{C}$. Comparison between experimental data (symbols) [59] and model predictions (lines).

It should be observed that the high temperature profile of levoglucosan is practically zero, because of its very high reactivity, as also experimentally observed. On the contrary, the predicted acetone decomposition at low temperatures is lower with respect to the wide scattered experimental measurements, which range between 0.0015 and 0.0044 . The reliability of the kinetic model of acetone decomposition was already proved in comparison with pyrolysis data of acetone-butanol, and ethanol $(A B E)$ mixture [61].

The kinetic model is able to predict with reasonable accuracy the formation of aromatic species. This is a mechanistic confirmation that aromatic hydrocarbons are mainly the result of successive condensation reactions, in agreement with the experimental and theoretical analysis of Norinaga et al. [59]. This feature will be emphasized in the successive application example, where higher 
temperatures and severity conditions further promote polycyclic-aromatic hydrocarbons (PAH) and soot formation.

Very recently, Yang et al. [60] investigated the vapor-phase reactions of nascent volatiles derived from the fast pyrolysis of lignin. The two-stage tubular reactor was used for evaluating the secondary gas phase reactions of the released species at temperatures from $500^{\circ} \mathrm{C}$ to $900^{\circ} \mathrm{C}$, at $241 \mathrm{kPa}$. The minimum residence time of volatiles before the detector was $0.1 \mathrm{~s}$, while it was modified inside the secondary pyrolysis reactor up to $3.6 \mathrm{~s}$. The lignin samples were prepared by enzymatic hydrolysis (EHL) of empty fruit bunches, with the elemental $\mathrm{C} / \mathrm{H} / \mathrm{O}$ composition of 63.5/5.93/30.57 (on a dry basis). Fast pyrolysis was realized in the first isothermal reactor, and well-resolved chromatograms were obtained in the entire temperature range. The characterization of the primary volatile products released by lignin includes a large amount of heavy undetectable phenolic species (>30\% at $773 \mathrm{~K})$, and this is a clear difficulty in simulating and comparing experimental data and model predictions. In simulating their experimental data, Yang et al. [60] observed that it was very helpful to add a global and empirical reaction to account for the contribution of tar and undetectable products in the gas-phase reactions. Their predictions without the global reaction largely under-estimated the yields of several major products. Therefore, they estimated the rate constant and stoichiometric coefficients of the global reaction by fitting, in a different way at the different temperatures, the experimental observations and the predicted results.

Table 5 reports the primary volatile products released from fast pyrolysis of lignin as experimentally measured after $0.1 \mathrm{~s}$ [60]. Very heavy phenolic species are not considered in the gas-phase kinetic scheme, because of the lumping approach. For this reason, the experimental 
data are here corrected by assuming the undetected heavy species as equally distributed between the lumped phenolic species and the solid char residue.

Predicted data, as obtained directly from lignin pyrolysis, and after $0.1 \mathrm{~s}$ at the pyrolysis temperature, are also reported. Comparisons between experimental data and model predictions indicate an overall reasonable agreement. The effect of secondary gas phase reactions with $0.1 \mathrm{~s}$ residence time is well evident at high temperatures. Namely, there is a significant decomposition of oxygenated species to form $\mathrm{CO}$ and $\mathrm{H}_{2}$, as well as a relevant formation of aromatic species, up to heavy PAHs.

\begin{tabular}{|c|c|c|c|c|c|c|c|c|c|c|}
\hline & & \multicolumn{3}{|c|}{ EXPERIMENTAL } & \multicolumn{6}{|c|}{ PREDICTED } \\
\hline & & \multicolumn{3}{|c|}{ Gas Phase (0.1 s) } & \multicolumn{3}{|c|}{$\begin{array}{l}\text { Primary pyrolysis }+0.1 \\
\text { s of secondary } \\
\text { reactions }\end{array}$} & \multicolumn{3}{|c|}{ Primary pyrolysis } \\
\hline \multicolumn{2}{|c|}{ TEMPERATURE [K] } & 773 & 1023 & 1223 & 773 & 1023 & 1223 & 773 & 1023 & 1223 \\
\hline \multicolumn{11}{|c|}{$\begin{array}{l}\text { PRODUCTS (wt\% of } \\
\text { initial) }\end{array}$} \\
\hline \multicolumn{2}{|c|}{$\mathrm{H}_{2}$} & 0.0 & 0.3 & 1.2 & 0.0 & 0.2 & 1.3 & 0.0 & 0.0 & 0.8 \\
\hline \multicolumn{2}{|l|}{$\mathrm{CO}$} & 1.0 & 15.0 & 33.1 & 7.6 & 13.1 & 32.0 & 7.6 & 9.6 & 19.8 \\
\hline \multicolumn{2}{|l|}{$\mathrm{CO}_{2}$} & 4.5 & 6.4 & 8.3 & 5.5 & 5.6 & 6.2 & 5.5 & 5.5 & 5.5 \\
\hline \multicolumn{2}{|l|}{$\mathrm{CH}_{4}$} & 1.2 & 4.1 & 6.7 & 0.3 & 1.3 & 5.9 & 0.3 & 0.7 & 3.6 \\
\hline \multicolumn{2}{|l|}{$\mathrm{C}_{2}$} & 0.3 & 2.5 & 3.6 & 2.2 & 2.8 & 5.9 & 2.2 & 2.5 & 4.8 \\
\hline \multicolumn{2}{|l|}{$\mathrm{C}_{3}-\mathrm{C}_{5}$} & 0.3 & 3.5 & 0.4 & 0.0 & 0.2 & 0.8 & 0.0 & 0.0 & 0.0 \\
\hline \multicolumn{2}{|l|}{ Aromatics $\left(\mathrm{C}_{6}+\right)$} & 0.2 & 3.3 & 8.4 & 0.0 & 1.5 & 5.6 & 0.0 & 0.0 & 0.0 \\
\hline \multirow{2}{*}{\multicolumn{2}{|c|}{$\begin{array}{l}\text { Light Oxygenated } \\
\text { Phenolic compounds* }\end{array}$}} & 5.7 & 3.8 & 0.1 & 7.1 & 6.6 & 2.1 & 7.1 & 9.1 & 9.3 \\
\hline & & 28.0 & 14.2 & 4.5 & 17.5 & 17.0 & 5.0 & 17.5 & 21.1 & 21.4 \\
\hline \multicolumn{2}{|c|}{$\mathrm{H}_{2} \mathrm{O}$} & 7.6 & 6.8 & 6.2 & 6.1 & 7.0 & 7.3 & 6.1 & 6.9 & 6.9 \\
\hline \multicolumn{2}{|l|}{ Total Volatiles } & 48.7 & 60.0 & 72.3 & 46.4 & 55.3 & 71.9 & 46.4 & 55.2 & 71.9 \\
\hline \multirow[b]{2}{*}{ TEMPERATURE } & & \multicolumn{4}{|c|}{ EXPERIMENTAL } & \multicolumn{5}{|c|}{ PREDICTED } \\
\hline & 773 & 923 & 1023 & 1123 & 1223 & 773 & 923 & 1023 & 1123 & 1223 \\
\hline Char* (wt\%) & 51.2 & 44.1 & 39.6 & 31.1 & 27.6 & 53.6 & 45.6 & 44.8 & 36.9 & 28.1 \\
\hline$C(w t \%)$ & 75.3 & 77.4 & 80.9 & 86.4 & 97.7 & 77.5 & 82.1 & 82.3 & 86.3 & 99.8 \\
\hline $\mathrm{H}(\mathrm{wt} \%)$ & 3.6 & 3.3 & 3.0 & 2.2 & 2.3 & 4.6 & 4.3 & 4.1 & 1.8 & 0.1 \\
\hline $\mathrm{O}$ (wt\%) & 21.1 & 19.3 & 16.0 & 11.3 & 0.0 & 17.9 & 13.6 & 13.6 & 11.9 & 0.2 \\
\hline
\end{tabular}

Table 5. Primary volatile products released from fast pyrolysis of lignin at $0.1 \mathrm{~s}$. Comparisons between experimental data [60] and model predictions. 


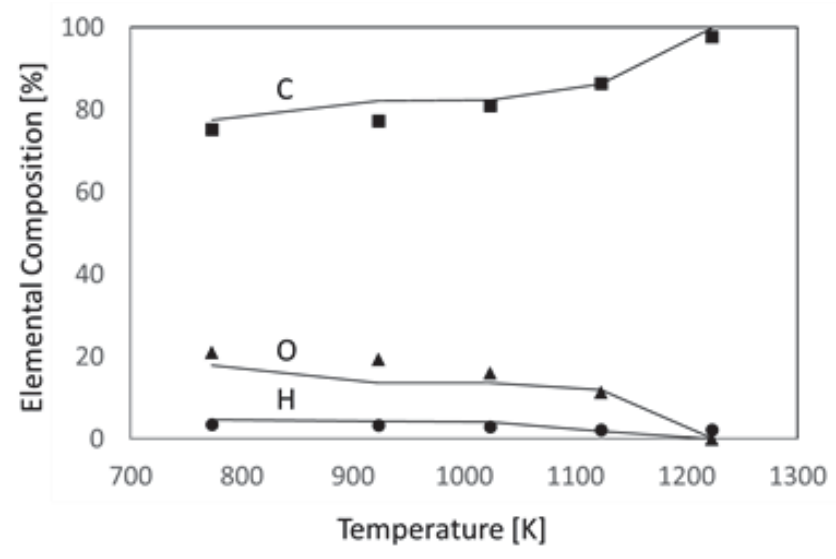

Figure 6. Carbon, hydrogen, and oxygen content in the residual char as a function of the pyrolysis temperature. Comparisons between experimental data (symbols) [60] and model predictions (lines).

Figure 6 shows the good agreement between experimental data and model predictions in terms of carbon, oxygen and hydrogen content in the char residue, as a function of the pyrolysis temperature. As expected, the oxygen and hydrogen content progressively decreases with increasing temperature.

Figure 7 compares experimental and model predictions of volatile species released from lignin pyrolysis at different temperatures with residence time of $3.6 \mathrm{~s}$ in the second tubular reactor [60]. Two different sets of model predictions are reported in Figure 7. The former set refers and uses the experimental information of product distribution from primary lignin pyrolysis reported in Table 5. Phenolic species, together with the undetected ones, were distributed according to the predicted primary pyrolysis products of the EHL sample. The second simulation results were obtained by directly feeding the EHL lignin sample to the two-stage tubular reactor. In this case, after the first pyrolysis stage, the predicted lignin pyrolysis products were fed to the second tubular reactor with the residence time of $3.6 \mathrm{~s}$. The reasonable agreement obtained with both these simulation procedures further confirms the predictive feature of the whole pyrolysis model, i.e. it is not necessary to use the experimental information on the primary decomposition products 
from lignin. In fact, the direct and coupled use of primary biomass pyrolysis together with successive gas-phase reactions give satisfactory predictions, very similar to the ones obtained by feeding the experimental primary products to the second reactor. There is a large underprediction of acetic acid, which deserves a special attention and a better analysis of its possible formation path from lignin pyrolysis. Recently, Mante et al. [62] observed that feedstocks with high lignin content, and possible interactions with polysaccharides, tend to produce high yields of oxygenated (hydroxyacetaldehyde and acetic acid).

An additional important aspect of these experiments relates to the very severe pyrolysis conditions, which cause significant formation of heavy PAHs and soot. Again, model results indicate in a predictive way the formation of $\sim 5 \%$ of species heavier than $C_{20}$, in agreement with the experimental observation of soot deposition on reactor walls above $1023 \mathrm{~K}$. The heaviest $\mathrm{C}_{20}$ $\mathrm{PAH}$ species act as the final sink of heavy carbonaceous species, because of the very severe pyrolysis conditions.

The comparisons with experimental data gives a further indication of the model capabilities to handle not only the initial biomass decomposition, but also the successive pyrolysis of the released products, in a completely predictive way. As already mentioned, typical applications both at particle and reactor scale have been already discussed in previous papers $[17,21]$, while the multiscale kinetic modeling and experimental investigation of syngas production from coal and biomass co-gasification in an updraft gasifier was recently analyzed by Corbetta et al. [63]. 

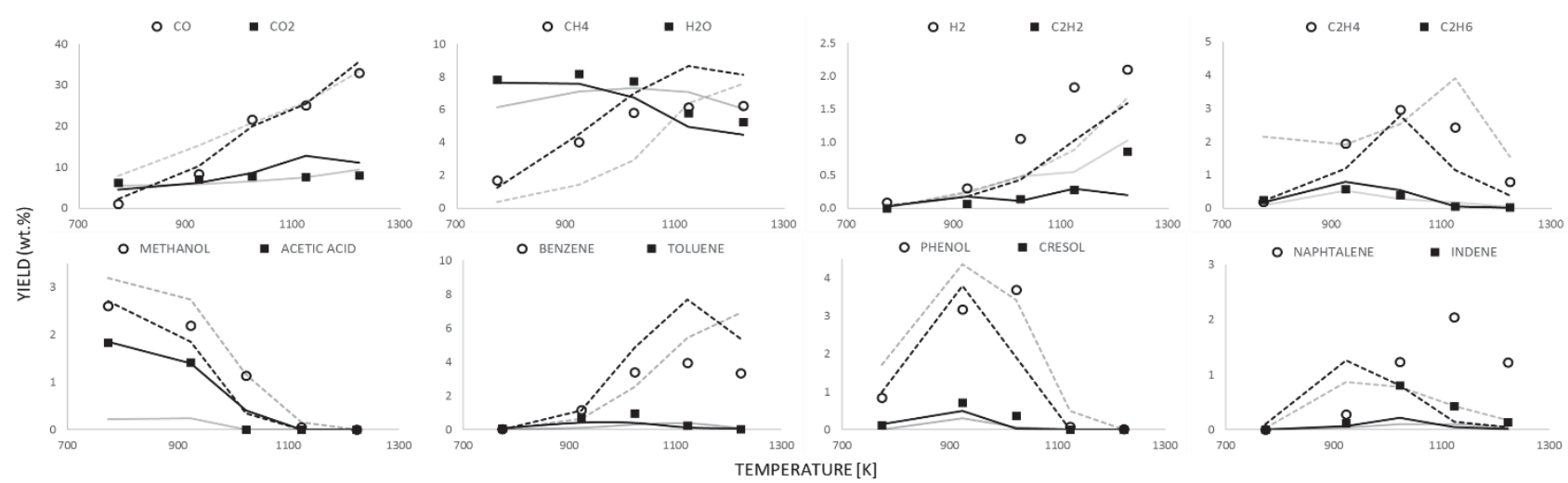

Figure 7. Volatile species released from lignin pyrolysis at different temperatures with residence time of $3.6 \mathrm{~s}$ in the second tubular reactor. Comparison between experimental data [60] (symbols) and model predictions with (dark lines) and without using the experimental intermediate data of lignin pyrolysis (light lines).

\section{Conclusion}

This work discusses and presents a general and predictive kinetic model of biomass pyrolysis, gasification, and combustion, with particular attention to the secondary gas phase reactions of pyrolysis products. Temperatures, characteristic times, efficiency, and pollutant emissions strongly depend on these reactions, which play a fundamental role to design reactors and to describe the whole process. A relevant feature of this predictive model, when compared to other devolatilization models, is the attempt to characterize pyrolysis reactions with a lumped stoichiometry using a limited number of equivalent components to describe not only gaseous products but also tar species. The model is completely predictive and only requires the ultimate biomass analysis. This model needs a high simplification level, for a viable coupling with the simultaneous mass- and heat-transfer resistances at the particle and the reactor scales. The biomass pyrolysis model involves only 21 species in the solid and metaplastic phase, while more than 400 species are involved in the gas phase reactions. The satisfactory comparisons with experimental data prove the model reliability, while the use at the reactor scale forces oversimplifications and these are the major model limitations. Since the original formulation [15], 
the model has been progressively extended and can be further improved in terms of kinetic parameters, new reaction steps, greater detail of reaction products, catalytic effect of ashes and/or interactions among reference species [64-66]. These extensions and improvements require new experimental data in ideal conditions, where it would be possible to distinguish the relative role of primary biomass devolatilization from the effect of secondary gas-phase reactions. To these purposes, the film pyrolysis experiments [67] and the very recent thermal-pulsing reactor of Krumm et al. [68], able to resolve the millisecond evolution of cellulose and biomass pyrolysis, seem very promising sources of new and useful experimental data.

\section{Acknowledgment}

The authors gratefully acknowledge the partial financial support for this research provided by the European Union under the Horizon 2020 research and innovation programme (Residue2Heat project, G.A. No 654650).

P.D. gratefully acknowledges the financial support from CAPES Foundation, Ministry of Education of Brazil-Science without Borders Mobility Program-Full PhD Scholarship Process No. 10131/13-2. 


\section{References}

[1] Antal MJJ, Varhegyi G. Cellulose pyrolysis kinetics: the current state of knowledge. Industrial \& Engineering Chemistry Research 1995;34:703.

[2] Zhou X, Nolte MW, Mayes HB, Shanks BH, Broadbelt LJ. Experimental and mechanistic modeling of fast pyrolysis of neat glucose-based carbohydrates. 1. Experiments and development of a detailed mechanistic model. Industrial \& Engineering Chemistry Research 2014;53:13274.

[3] Zhou X, Nolte MW, Shanks BH, Broadbelt L. Experimental and mechanistic modeling of fast pyrolysis of neat glucose-based carbohydrates. 2. Validation and evaluation of the mechanistic model. Industrial \& Engineering Chemistry Research 2014;53:13290.

[4] Rodrigues, M., Faaij, A. P., \& Walter, A. (2003). Techno-economic analysis of co-fired biomass integrated gasification/combined cycle systems with inclusion of economies of scale. Energy, 28(12), 1229-1258.

[5] Evans, R. J., \& Milne, T. A. (1987). Molecular characterization of the pyrolysis of biomass. Energy \& Fuels, 1(2), 123-137.

[6] Shen D, Jin W, Hu J, Xiao R, Luo K. An overview on fast pyrolysis of the main constituents in lignocellulosic biomass to valued-added chemicals: Structures, pathways and interactions. Renewable and Sustainable Energy Reviews 2015;51:761.

[7] Carstensen H-H, Dean AM. Development of detailed kinetic models for the thermal conversion of biomass via first principle methods and rate estimation rules. Computational Modeling in Lignocellulosic Biofuel Production 2010:201.

[8] Debiagi PEA, Pecchi C, Gentile G, Frassoldati A, Cuoci A, Faravelli T, et al. Extractives extend the applicability of multistep kinetic scheme of biomass pyrolysis. Energy \& Fuels 2015;29:6544.

[9] Lindfors C, Kuoppala E, Oasmaa A, Solantausta Y, Arpiainen V. Fractionation of bio-oil. Energy \& Fuels 2014;28:5785.

[10] Djokic MR, Dijkmans T, Yildiz G, Prins W, Van Geem KM. Quantitative analysis of crude and stabilized bio-oils by comprehensive two-dimensional gas-chromatography. Journal of Chromatography A 2012;1257:131.

[11] Yildiz G, Pronk M, Djokic M, van Geem KM, Ronsse F, Van Duren R, et al. Validation of a new set-up for continuous catalytic fast pyrolysis of biomass coupled with vapour phase upgrading. Journal of Analytical and Applied Pyrolysis 2013;103:343.

[12] Weng J, Jia L, Wang Y, Sun S, Tang X, Zhou Z, et al. Pyrolysis study of poplar biomass by tunable synchrotron vacuum ultraviolet photoionization mass spectrometry. Proceedings of the Combustion Institute 2013;34:2347.

[13] Miller RS, Bellan J. A generalized biomass pyrolysis model based on superimposed cellulose, hemicelluloseand liqnin kinetics. Combustion science and technology 1997;126:97.

[14] Grønli MG, Varhegyi G, Di Blasi C. Thermogravimetric analysis and devolatilization kinetics of wood. Industrial \& Engineering Chemistry Research 2002;41:4201.

[15] Ranzi E, Cuoci A, Faravelli T, Frassoldati A, Migliavacca G, Pierucci S, et al. Chemical kinetics of biomass pyrolysis. Energy \& Fuels 2008;22:4292.

[16] Faravelli T, Frassoldati A, Migliavacca G, Ranzi E. Detailed kinetic modeling of the thermal degradation of lignins. Biomass and bioenergy 2010;34:290. 
[17] Corbetta M, Frassoldati A, Bennadji H, Smith K, Serapiglia MJ, Gauthier G, et al. Pyrolysis of centimeter-scale woody biomass particles: Kinetic modeling and experimental validation. Energy \& Fuels 2014;28:3884.

[18] Seshadri V, Westmoreland PR. Concerted reactions and mechanism of glucose pyrolysis and implications for cellulose kinetics. The Journal of Physical Chemistry A 2012;116:11997.

[19] Vinu R, Broadbelt $\amalg$. A mechanistic model of fast pyrolysis of glucose-based carbohydrates to predict bio-oil composition. Energy \& Environmental Science 2012;5:9808.

[20] Burnham AK, Zhou X, Broadbelt L. Critical Review of the Global Chemical Kinetics of Cellulose Thermal Decomposition. Energy \& Fuels 2015;29:2906.

[21] Ranzi E, Corbetta M, Manenti F, Pierucci S. Kinetic modeling of the thermal degradation and combustion of biomass. Chemical Engineering Science 2014;110:2.

[22] Stark AK, Bates RB, Zhao Z, Ghoniem AF. Prediction and validation of major gas and tar species from a reactor network model of air-blown fluidized bed biomass gasification. Energy \& Fuels 2015;29:2437.

[23] Caballero J, Conesa J, Font R, Marcilla A. Pyrolysis kinetics of almond shells and olive stones considering their organic fractions. Journal of Analytical and Applied Pyrolysis 1997;42:159.

[24] Catoire L, Yahyaoui M, Osmont A, Gökalp I, Brothier M, Lorcet HIn, et al. Thermochemistry of compounds formed during fast pyrolysis of lignocellulosic biomass. Energy \& Fuels 2008;22:4265.

[25] Ince A, Carstensen HH, Reyniers MF, Marin GB. First-principles based group additivity values for thermochemical properties of substituted aromatic compounds. AlChE Journal 2015;61:3858.

[26] Ranzi E, Frassoldati A, Stagni A, Pelucchi M, Cuoci A, Faravelli T. Reduced Kinetic Schemes of Complex Reaction Systems: Fossil and Biomass-Derived Transportation Fuels. International Journal of Chemical Kinetics 2014;46:512.

[27] Curran H, Gaffuri P, Pitz WJ, Westbrook CK. A comprehensive modeling study of $n$-heptane oxidation. Combustion and Flame 1998;114:149.

[28] Ranzi E, Gaffuri P, Faravelli T, Dagaut P. A wide-range modeling study of $n$-heptane oxidation. Combustion and flame 1995;103:91.

[29] Westbrook CK, Warnatz J, Pitz WJ. A detailed chemical kinetic reaction mechanism for the oxidation of iso-octane and $n$-heptane over an extended temperature range and its application to analysis of engine knock. Symposium (international) on combustion: Elsevier; 1989, p. 893.

[30] Côme G, Warth V, Glaude P, Fournet R, Battin-Leclerc F, Scacchi G. Computer-aided design of gas-phase oxidation mechanisms-application to the modeling of $n$-heptane and iso-octane oxidation. Symposium (International) on Combustion: Elsevier; 1996, p. 755.

[31] Ranzi E, Cavallotti C, Cuoci A, Frassoldati A, Pelucchi M, Faravelli T. New reaction classes in the kinetic modeling of low temperature oxidation of $n$-alkanes. Combustion and flame 2015;162:1679.

[32] Bugler J, Somers KP, Silke EJ, Curran HJ. Revisiting the kinetics and thermodynamics of the low-temperature oxidation pathways of alkanes: A case study of the three pentane isomers. The Journal of Physical Chemistry A 2015;119:7510.

[33] Dente M, Pierucci S, Ranzi E, Bussani G. New improvements in modeling kinetic schemes for hydrocarbons pyrolysis reactors. Chemical engineering science 1992;47:2629.

[34] Ranzi E, Dente M, Faravelli T, Pennati G. Prediction of kinetic parameters for hydrogen abstraction reactions. Combustion science and technology 1993;95:1. 
[35] Carstensen HH, Dean AM. A quantitative kinetic analysis of CO elimination from phenoxy radicals. International Journal of Chemical Kinetics 2012;44:75.

[36] Curtiss LA, Redfern PC, Raghavachari K. Gaussian-4 theory using reduced order perturbation theory. The Journal of chemical physics 2007;127:124105.

[37] Frisch M, Trucks G, Schlegel H, Scuseria G, Robb M, Cheeseman J, et al. Gaussian 09, Revision A. 1. Wallingford CT: Gaussian. Inc; 2009.

[38] Oyeyemi VB, Keith JA, Carter EA. Trends in Bond Dissociation Energies of Alcohols and Aldehydes Computed with Multireference Averaged Coupled-Pair Functional Theory. The Journal of Physical Chemistry A 2014;118:3039.

[39] Pelucchi, M., Cavallotti, C., Ranzi, E., Frassoldati, A., Faravelli, T. Relative reactivity of oxygenated fuels: alcohols, aldehydes, ketons and methyl esters. Submitted to Energy\&Fuels, 2016 [40] Ranzi E, Dente M, Pierucci S, Biardi G. Initial product distributions from pyrolysis of normal and branched paraffins. Industrial \& Engineering Chemistry Fundamentals 1983;22:132.

[41] Frassoldati A, Cuoci A, Faravelli T, Niemann U, Ranzi E, Seiser R, et al. An experimental and kinetic modeling study of $n$-propanol and iso-propanol combustion. Combustion and Flame 2010;157:2.

[42] Grana R, Frassoldati A, Faravelli T, Niemann U, Ranzi E, Seiser R, et al. An experimental and kinetic modeling study of combustion of isomers of butanol. Combustion and Flame 2010;157:2137.

[43] Curran H. Rate constant estimation for $\mathrm{C} 1$ to $\mathrm{C} 4$ alkyl and alkoxyl radical decomposition. International journal of chemical kinetics 2006;38:250.

[44] Pelucchi M, Somers KP, Yasunaga K, Burke U, Frassoldati A, Ranzi E, et al. An experimental and kinetic modeling study of the pyrolysis and oxidation of $n-C 3 C 5$ aldehydes in shock tubes. Combustion and Flame 2015;162:265.

[45] Frassoldati A, Grana R, Faravelli T, Ranzi E, Oßwald P, Kohse-Höinghaus K. Detailed kinetic modeling of the combustion of the four butanol isomers in premixed low-pressure flames. Combustion and Flame 2012;159:2295.

[46] Nimlos, M. R., Blanksby, S. J., Ellison, G. B., \& Evans, R. J. (2003). Enhancement of 1, 2dehydration of alcohols by alkali cations and protons: a model for dehydration of carbohydrates. Journal of analytical and applied pyrolysis, 66(1), 3-27.

[47] Sarathy SM, Oßwald P, Hansen N, Kohse-Höinghaus K. Alcohol combustion chemistry. Progress in Energy and Combustion Science 2014;44:40.

[48] Barker-Hemings E, Cavallotti C, Cuoci A, Faravelli T, Ranzi E. A detailed kinetic study of pyrolysis and oxidation of glycerol (propane-1, 2, 3-triol). Combustion Science and Technology 2012;184:1164.

[49] Mayes, H. B., Nolte, M. W., Beckham, G. T., Shanks, B. H., \& Broadbelt, L. J. (2014). The Alpha-Bet (a) of Glucose Pyrolysis: Computational and Experimental Investigations of 5Hydroxymethylfurfural and Levoglucosan Formation Reveal Implications for Cellulose Pyrolysis. ACS Sustainable Chemistry \& Engineering, 2(6), 1461-1473.

[50] Saggese C, Ferrario S, Camacho J, Cuoci A, Frassoldati A, Ranzi E, et al. Kinetic modeling of particle size distribution of soot in a premixed burner-stabilized stagnation ethylene flame. Combustion and Flame 2015;162:3356.

[51] Saggese C, Frassoldati A, Cuoci A, Faravelli T, Ranzi E. A wide range kinetic modeling study of pyrolysis and oxidation of benzene. Combustion and Flame 2013;160:1168. 
[52] Djokic MR, Van Geem KM, Cavallotti C, Frassoldati A, Ranzi E, Marin GB. An experimental and kinetic modeling study of cyclopentadiene pyrolysis: First growth of polycyclic aromatic hydrocarbons. Combustion and Flame 2014;161:2739.

[53] Barker-Hemings E, Bozzano G, Dente M, Ranzi E. Detailed kinetics of the pyrolysis and oxidation of anisole. Chem Eng Trans 2011;24:61.

[54] Nowakowska M, Herbinet O, Dufour A, Glaude P-A. Detailed kinetic study of anisole pyrolysis and oxidation to understand tar formation during biomass combustion and gasification. Combustion and Flame 2014;161:1474.

[55] Pecullan M, Brezinsky K, Glassman I. Pyrolysis and oxidation of anisole near $1000 \mathrm{~K}$. The Journal of Physical Chemistry A 1997;101:3305.

[56] Calonaci M, Grana R, Barker Hemings E, Bozzano G, Dente M, Ranzi E. Comprehensive kinetic modeling study of bio-oil formation from fast pyrolysis of biomass. Energy \& Fuels 2010;24:5727.

[57] Dupont C, Chen L, Cances J, Commandre J-M, Cuoci A, Pierucci S, et al. Biomass pyrolysis: Kinetic modelling and experimental validation under high temperature and flash heating rate conditions. Journal of Analytical and Applied Pyrolysis 2009;85:260.

[58] Ranzi E, Pierucci S, Aliprandi PC, Stringa S. Comprehensive and detailed kinetic model of a traveling grate combustor of biomass. Energy \& Fuels 2011;25:4195.

[59] Norinaga K, Shoji T, Kudo S, Hayashi J-i. Detailed chemical kinetic modelling of vapourphase cracking of multi-component molecular mixtures derived from the fast pyrolysis of cellulose. Fuel 2013;103:141.

[60] Yang H-M, Appari S, Kudo S, Hayashi J-i, Norinaga K. Detailed Chemical Kinetic Modeling of Vapor-Phase Reactions of Volatiles Derived from Fast Pyrolysis of Lignin. Industrial \& Engineering Chemistry Research 2015;54:6855.

[61] Van Geem, K. M., Cuoci, A., Frassoldati, A., Pyl, S. P., Marin, G. B., \& Ranzi, E. (2012). An experimental and kinetic modeling study of pyrolysis and combustion of acetone-butanol-ethanol (ABE) mixtures. Combustion Science and Technology, 184(7-8), 942-955.

[62] Mante OD, Babu SP, Amidon TE. A comprehensive study on relating cell-wall components of lignocellulosic biomass to oxygenated species formed during pyrolysis. Journal of Analytical and Applied Pyrolysis 2014;108:56.

[63] Corbetta M, Bassani A, Manenti F, Pirola C, Maggio E, Pettinau A, et al. Multi-scale kinetic modeling and experimental investigation of syngas production from coal gasification in updraft gasifiers. Energy \& Fuels 2015;29:3972.

[64] Gargiulo V, Giudicianni P, Alfè M, Ragucci R. Influence of possible interactions between biomass organic components and alkali metal ions on steam assisted pyrolysis: A case study on Arundodonax. Journal of Analytical and Applied Pyrolysis 2015;112:244.

[65] Trendewicz A, Evans R, Dutta A, Sykes R, Carpenter D, Braun R. Evaluating the effect of potassium on cellulose pyrolysis reaction kinetics. Biomass and Bioenergy 2015;74:15.

[66] Anca-Couce A. Reaction mechanisms and multi-scale modelling of lignocellulosic biomass pyrolysis. Progress in Energy and Combustion Science 2016;53:41.

[67] Mettler, M. S., Vlachos, D. G., \& Dauenhauer, P. J. (2012). Top ten fundamental challenges of biomass pyrolysis for biofuels. Energy \& Environmental Science, 5(7), 7797-7809.

[68] Krumm, C., Pfaendtner, J., \& Dauenhauer, P. J. (2016). Millisecond Pulsed Films Unify the Mechanisms of Cellulose Fragmentation. Chemistry of Materials. 28 (9), 3108-3114 